\title{
SIMULTANEOUS ESTIMATION AND FORCED DEGRADATION STUDIES OF AMILORIDE HYDROCHLORIDE AND FUROSEMIDE IN A PHARMACEUTICAL DOSAGE FORM USING REVERSE-PHASE HIGH-PERFORMANCE LIQUID CHROMATOGRAPHY METHOD
}

\author{
JAVED S SHAIKH, NUTAN N RAO* \\ Department of Quality Assurance, Oriental College of Pharmacy, Sanpada, Navi Mumbai, Maharashtra - 400 705, India. \\ Email: nutan.rao@ocp.edu.in
}

Received: 09 March 2018, Revised and Accepted: 05 April 2018

ABSTRACT

Objective: The present study describes the stability indicating reverse-phase high-performance liquid chromatography (RP-HPLC) method for simultaneous estimation of amiloride hydrochloride and furosemide in pharmaceutical dosage forms.

Methods: The proposed RP-HPLC method was developed using Shimadzu LC-2030 HPLC system equipped with UV detector, and chromatographic separation was carried on Shim-pack C18 $(250 \mathrm{~mm} \times 4.6 \mathrm{~mm}, 5 \mu)$ column at a flow rate of $1 \mathrm{ml} / \mathrm{min}$ and the runtime was $4 \mathrm{~min}$. The mobile phase consisted of water and acetonitrile in the ratio of 35:65, and elements were scanned using a UV detector at $281 \mathrm{~nm}$.

Results: The retention time of amiloride hydrochloride and furosemide was found to be $1.92 \mathrm{~min}$ and $3.14 \mathrm{~min}$, respectively. Linearity was found to be 12-28 ppm for amiloride hydrochloride and 96-224 ppm for furosemide, respectively. Limit of detection and limit of quantification for amiloride hydrochloride were $0.381 \mathrm{ppm}$ and $1.156 \mathrm{ppm}$ and for furosemide were $2.00 \mathrm{ppm}$ and $6.068 \mathrm{ppm}$, respectively.

Conclusion: The stability indicating method was developed by subjecting the drugs to stress conditions such as acid and base hydrolysis, oxidation, humidity, photolytic, and thermal degradation, and the degraded products formed were resolved successfully from the samples.

Keywords: Amiloride hydrochloride, Furosemide, Reverse-phase high-performance liquid chromatography, Degradation, Validation, ICH.

(C) 2018 The Authors. Published by Innovare Academic Sciences Pvt Ltd. This is an open access article under the CC BY license (http://creativecommons. org/licenses/by/4. 0/) DOI: http://dx.doi.org/10.22159/ajpcr.2018.v11i7.25783

\section{INTRODUCTION}

Amiloride hydrochloride is a potassium-sparing diuretic. It is chemically 3,5-diamino- $\mathrm{N}$-(diaminomethylene)-6-chloropyrazinecarboxami demonohydr ochloridedihydrate [1,2] (Fig. 1). It works by inhibiting sodium reabsorption in renal epithelial cells by binding to sodium channels. Inhibition of sodium reabsorption creates a negative voltage in the luminal membranes of principal cells, situated at the distal convoluted tubule and collecting duct. This negative voltage decreases the potassium and hydrogen ion secretion [2,3]. It is used in conjunction with diuretics to spare potassium loss.

Furosemide is a loop diuretic. It is chemically 4-chloro-2-furfurylamino-5sulphamoyl benzoic acid (Fig. 1). Furosemide inhibits water reabsorption in the nephron by blocking sodium and chloride reabsorption in the ascending limb of the loop of Henle [4]. Furosemide helps to maintain potassium and minimize the risk of alkalosis, in the treatment of edema associated with hepatic cirrhosis and congestive heart failure [2,5].

The thorough literature survey reveals that few analytical methods such as RP-HPLC and UV methods are reported for simultaneous estimation of amiloride hydrochloride and furosemide in pharmaceutical dosage forms $[3,6,7]$. Thus, the present investigation was held out to acquire new, simple, accurate, rapid, and cost-effective stability indicating RP-HPLC method for the simultaneous estimation of amiloride hydrochloride and furosemide in pharmaceutical dosage form. The suggested method was applied successfully to split up the degraded products from the samples.

\section{METHODS}

Reagents and chemicals

Amiloride hydrochloride and furosemide standards were provided by Alkem Laboratories, Navi Mumbai, Maharashtra, India, and Yarrow
Chem Products, Dombivili, Maharashtra, India. Commercial tablet dosage form, Frumil, was purchased from local markets. The HPLC grade acetonitrile and water were purchased from Thomas Baker. Analytical grade orthophosphoric acid (OPA), hydrochloric acid, sodium hydroxide, and hydrogen peroxide were purchased from S.D. Fine Chemicals.

\section{Instrument}

The chromatographic separation was carried out by Shimadzu LC2030 HPLC system equipped with UV detector and autosampler. The LabSolution software was used for signal monitoring and processing. Photolytic degradation was done in UV chamber, and hot air oven was employed for thermal degradation.

\section{Selection of wavelength}

Both the drugs were scanned by UV individually, in a wavelength range of 200-400 $\mathrm{nm}$ and maxima for each drug was measured. The corresponding UV spectrum graphs of the drugs such as amiloride hydrochloride and hydrochlorothiazide are shown in Fig. 2. The detection wavelength was selected from the overlay UV spectrum and was found to be $281 \mathrm{~nm}$.

\section{Chromatographic conditions}

The chromatographic separation of analytes was carried out using ShimadzuRP-HPLC system with Shim-pack GIST C18 $(250 \times 4.6 \mathrm{~mm}$, $5 \mu$ ) column. The mobile phase of a mixture of water and acetonitrile was in the ratio of 35:65 and column temperature was maintained at $25^{\circ} \mathrm{C}$. The analytes were detected at $281 \mathrm{~nm}$ using UV detector. The runtime was set at $4 \mathrm{~min}$ at a flow rate of $1 \mathrm{ml} / \mathrm{min}$.

\section{Preparation of standard stock solution}

Standard stock solutions of amiloride hydrochloride and furosemide were prepared separately by dissolving $100 \mathrm{mg}$ of amiloride hydrochloride and $100 \mathrm{mg}$ of furosemide in $100 \mathrm{ml}$ volumetric flasks 


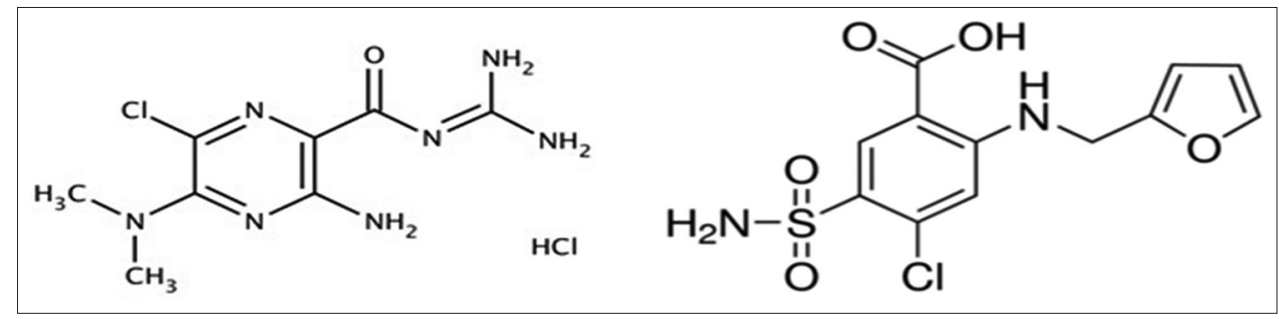

Fig. 1: Structure of amiloride hydrochloride and furosemide

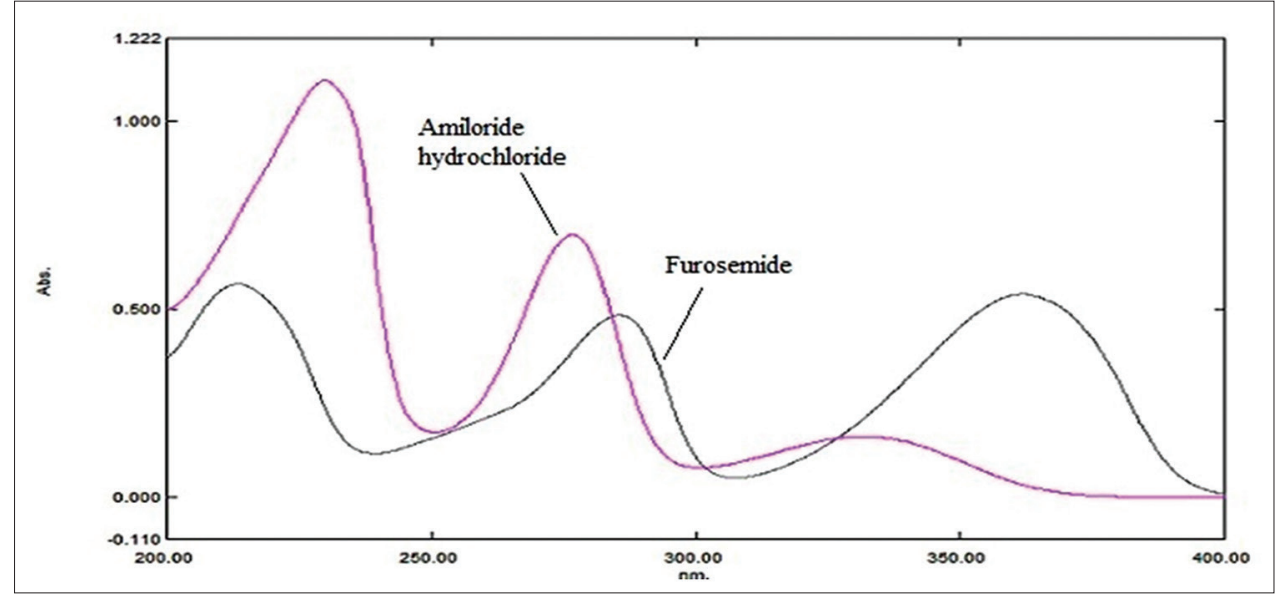

Fig. 2: Overlain spectra of amiloride hydrochloride and furosemide

with water:acetonitrile (35:65) as diluent and sonicated for $10 \mathrm{~min}$. From the above solution, $0.2 \mathrm{ml}$ of amiloride hydrochloride and 1.6 $\mathrm{ml}$ of furosemide were transferred separately to $10 \mathrm{ml}$ volumetric flasks, and $1 \mathrm{ml} 5 \%$ OPA was added as a supporter and sonicated for $5 \mathrm{~min}$ and made up the volume with diluent to get $20 \mathrm{ppm}$ of amiloride hydrochloride and $160 \mathrm{ppm}$ of furosemide standard stock solution.

\section{Preparation of sample solution}

Ten tablets (Frumil tablets: $5 \mathrm{mg}$ amiloride hydrochloride and $40 \mathrm{mg}$ furosemide) were weighed and the average weight of each tablet was calculated; then, the weight equivalent to 1 tablet was transferred into a $100 \mathrm{ml}$ clean dry volumetric flask, add $30 \mathrm{ml}$ of diluent, sonicated for $25 \mathrm{~min}$, and make up to the final volume with diluent and filtered. $2 \mathrm{ml}$ of the filtered solution was pipetted out into a $10 \mathrm{ml}$ volumetric flask and $1 \mathrm{ml} 5 \%$ of the OPA was added as a supporter and sonicated for $5 \mathrm{~min}$, and volume made up to $10 \mathrm{ml}$ with diluent.

\section{Method validation}

The method validation was done according to the ICH guidelines with above developed RP-HPLC method for simultaneous estimation of amiloride hydrochloride and furosemide. Several parameters were evaluated such as system suitability, precision, accuracy, linearity, robustness, limit of detection (LOD), and limit of quantification (LOQ) [8,9].

\section{Forced degradation studies}

The ICH degradation was attempted under various stress conditions such as acid, alkaline, oxidation, thermal, humidity, and photolytic conditions to evaluate the interference of degradation impurities. These studies help to know the inherent stability characteristic of the active molecules in drug product and the possible degradation products.

Acid, base, and oxidation degradations were performed by adding $5 \mathrm{ml}$ of $1 \mathrm{~N} \mathrm{HCl}, 5 \mathrm{ml}$ of $1 \mathrm{~N} \mathrm{NaOH}$, and $5 \mathrm{ml}$ of $30 \%$ peroxide solution $\left(\mathrm{H}_{2} \mathrm{O}_{2}\right)$, respectively, to the sample solutions, and these samples were kept at room temperature for $3 \mathrm{~h}$. Thermal degradation was performed by keeping the tablets in a Petri dish and then placed them in an oven at $105^{\circ} \mathrm{C}$ for $48 \mathrm{~h}$. Humidity degradation was performed by placing the tablets in a Petri dish and kept in a humidity chamber at $95 \%$ relative humidity, at $25^{\circ} \mathrm{C}$ for $120 \mathrm{~h}$. A photolytic degradation study was carried out by placing the tablets in a Petri dish in a photolytic chamber for 7 days.

\section{RESULTS AND DISCUSSION}

\section{Method development}

A series of tests was taken with different columns such as Inertsil ODS and Shim-pack C18 column with different mobile phases to produce a suitable RP-HPLC method for estimation of amiloride hydrochloride and furosemide in tablet dosage form, and finally, a typical chromatogram was obtained with water and acetonitrile in the ratio of 35:65. The chromatographic separation was performed on Shim-Pack C18 $(250 \times 4.6 \mathrm{~mm}, 5 \mu)$ column by injecting $20 \mu \mathrm{L}$, and the analytes were detected with UV detector at $281 \mathrm{~nm}$. The retention time of amiloride hydrochloride and furosemide was found to be $1.92 \mathrm{~min}$ and $3.14 \mathrm{~min}$, respectively. Forced degradation studies for amiloride hydrochloride and hydrochlorothiazide in tablet dosage form were also carried out using the developed method, and the degraded compounds were effectively resolved. The optimized conditions were given in Table 1 and Fig. 3 .

\section{System suitability}

System suitability was performed to verify the acceptability of the resolution and repeatability of the system. System suitability was performed by injecting six replicate injections of the standard solution $(100 \%)$, and parameters such as peak area, USP tailing, theoretical plates, retention time, and peak asymmetry were evaluated. The \% relative standard deviation (RSD) was determined and reported within the limits [10]. The results are shown in Table 2.

\section{Accuracy}

The accuracy of the proposed method was evaluated by calculating the recovery studies of the test drug at three different concentration levels $(80 \%, 100 \%$, and $120 \%)$ by the standard addition method [11]. A known amount of amiloride hydrochloride and furosemide was added to the prequantified sample solution, and three replicates of each concentration 


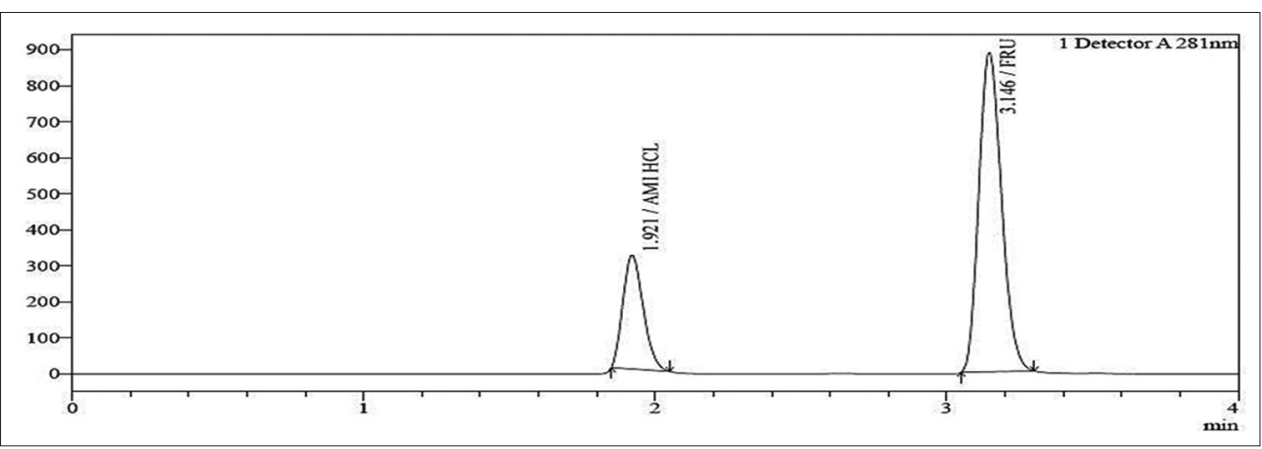

Fig. 3: Chromatogram of standard amiloride hydrochloride and furosemide

Table 1: Optimized chromatographic condition

\begin{tabular}{ll}
\hline Parameter & Optimized condition \\
\hline Column & Shim-Pack C18 $(250 \times 4.6 \mathrm{~mm}, 5 \mu)$ column \\
Mobile phase & Water and acetonitrile in the ratio of 35:65 \\
Flow rate & $1 \mathrm{ml} / \mathrm{min}$ \\
Wavelength & UV detector at $281 \mathrm{~nm}$ \\
Injection volume & $20 \mu \mathrm{L}$ \\
Temperature & $25^{\circ} \mathrm{C}$ \\
Retention time & Amiloride hydrochloride 1.921 min and \\
& furosemide 3.146 min \\
\hline
\end{tabular}

Table 2: System suitability parameters

\begin{tabular}{lll}
\hline Parameters & $\begin{array}{l}\text { Amiloride } \\
\text { hydrochloride }\end{array}$ & Furosemide \\
\hline Retention time (min) & 1.921 & 3.146 \\
USP plate count & 2876 & 6454 \\
USP tailing & 1.243 & 1.191 \\
\hline
\end{tabular}

were injected into developing chromatographic conditions. The percentage recovery result of amiloride hydrochloride and furosemide was found to be within limits of 100-101\%, indicating that the developed method was found to be accurate. The percentage recovery results are shown in Table 3.

\section{Precision}

The precision of an analytical procedure may be defined as the closeness of agreement between a series of measurements obtained from multiple sampling of the same homogeneous sample under the prescribed conditions. The method precision and system precision studies were carried out by injecting six replicates of both standard and test solutions with the same concentration [12]. The \% RSD was calculated from the chromatogram and the results obtained were within the limits of $2 \%$, and the proposed method was found to be precise. The precision data are given in Table 4 .

\section{Linearity}

The linearity of the method was determined at different concentration levels ranging from 12 to $28 \mathrm{ppm}$ of amiloride hydrochloride and from 96 to $224 \mathrm{ppm}$ of furosemide. All the concentrations were prepared and injected into the system. The linearity curve was constructed by plotting peak area versus concentration of the analyte. From the results obtained, the proposed method was found to be linear. The regression coefficient $\left(r^{2}\right)$ was found to be 0.999 and 0.999 for amiloride hydrochloride and furosemide, respectively, and the result is shown in Fig. 4.

\section{LOD and LOQ}

In the present study, the LOD and LOQ of amiloride hydrochloride and furosemide were evaluated based on the standard calibration curve method [13]. LOD is performed to know the lowest concentration level of the analyte that gives a measurable response. LOD and LOQ for amiloride hydrochloride are $0.381 \mathrm{ppm}$ and $1.156 \mathrm{ppm}$ and for furosemide are $2.00 \mathrm{ppm}$ and $6.068 \mathrm{ppm}$, respectively.

\section{Robustness}

Robustness of the proposed method has been evaluated by small deliberate changes in the system parameters such as flow rate, wavelength, and temperature [14]. It was found that none of the above parameters caused an alteration in the peak area, retention time, and USP tailing by small changes such as $\pm 0.2 \mathrm{ml}$ change in flow rate, $\pm 2 \mathrm{~nm}$ wavelength, and $\pm 2{ }^{\circ} \mathrm{C}$ changes in temperature. The \% RSD was found to be within the limits, and the method was found to be robust. The robustness results are shown in Table 5.

\section{Assay of marketed formulation}

Analysis of marketed formulation (Frumil tablets: $5 \mathrm{mg}$ amiloride hydrochloride and $40 \mathrm{mg}$ furosemide) was purchased from local markets. Ten tablets were weighed and average weight of each tablet was calculated; then, the weight equivalent to 1 tablet was transferred into a $100 \mathrm{ml}$ clean dry volumetric flask, add $30 \mathrm{ml}$ of diluent, sonicated for $25 \mathrm{~min}$, and make up to the final volume with diluent and filtered. $2 \mathrm{ml}$ of the filtered solution was pipetted out into a $10 \mathrm{ml}$ volumetric flask, and $1 \mathrm{ml} 5 \%$ of OPA is added as a supporter and made up to $10 \mathrm{ml}$ with diluent. From the resulting solution, $20 \mu \mathrm{L}$ was injected into HPLC system and peak areas were recorded. The \% assay of the marketed formulation was found to be $99.55 \%$ for amiloride hydrochloride and $99.9 \%$ for furosemide as shown in Table 6.

\section{Forced degradation studies}

Forced degradation studies of the drug formulation were carried out by treating the drug samples under stress-induced conditions such as acid and base hydrolysis, oxidation, humidity, and photo- and thermal-degradation to evaluate the ability of the proposed method to separate amiloride hydrochloride and furosemide from its degradation products as shown in Figs. 5-11. The \% assay of amiloride hydrochloride and furosemide with respect to untreated sample and \% assay results obtained from treating the samples with various stress conditions had a difference which was within the acceptable limits. The results of stress studies are shown in Table 7.

\section{Acid degradation}

Acid (1 N hydrochloric acid) degradation study showed 1.3\% and 1.9\% degradation for amiloride hydrochloride and furosemide, respectively. However, no degradation product was observed in the chromatogram (Fig. 6).

\section{Alkali degradation}

The degradation in base (1 $\mathrm{N}$ sodium hydroxide) was found to be $1.1 \%$ and $3.9 \%$ for amiloride hydrochloride and furosemide, respectively. However, no degradation product was observed in the chromatogram (Fig. 7).

\section{Oxidative degradation}

Oxidative degradation study in 30\% hydrogen peroxide gave around $2.2 \%$ and $6.9 \%$ for amiloride hydrochloride and furosemide, respectively. However, no degradation product was observed in the chromatogram (Fig. 8). 


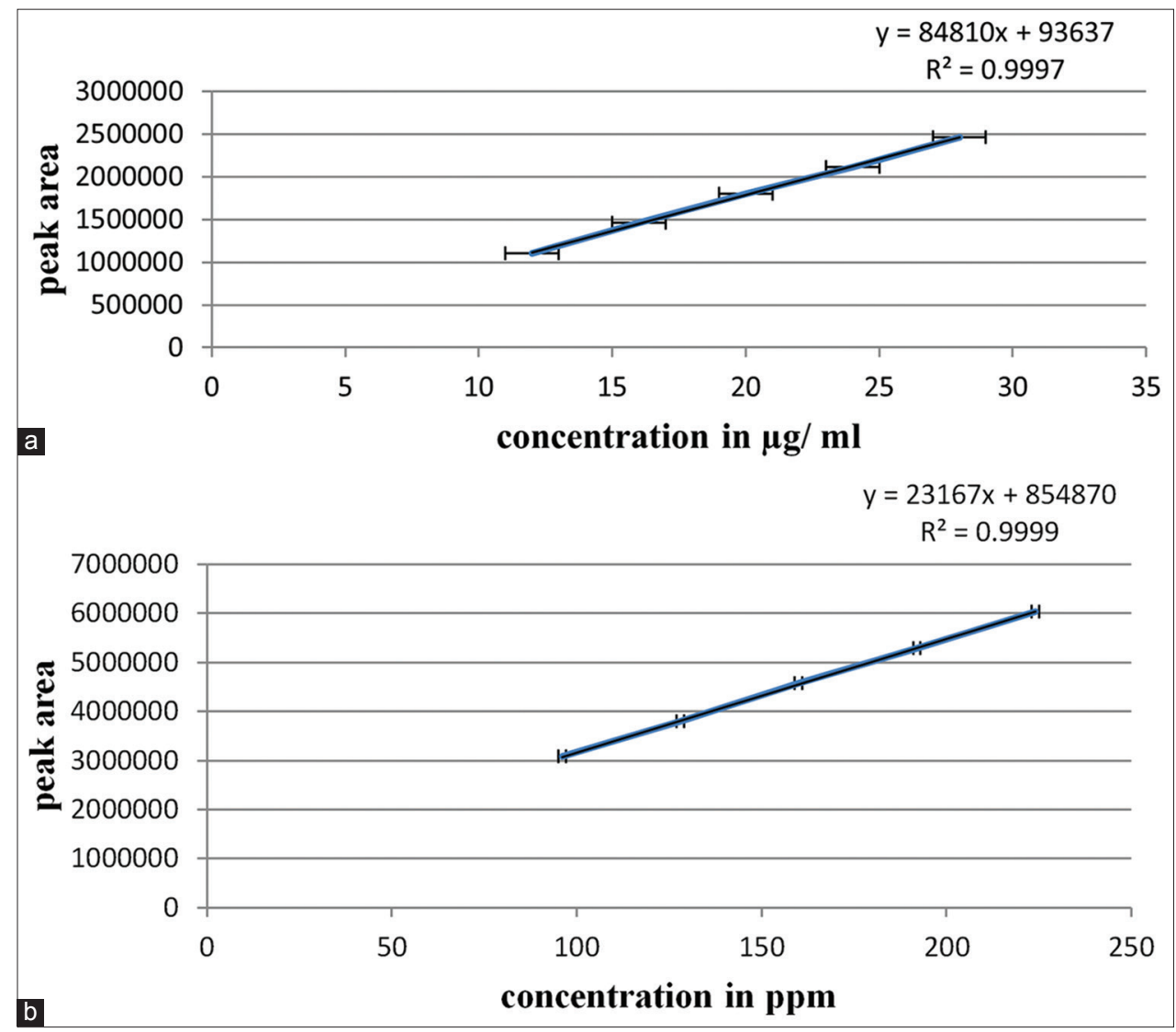

Fig. 4: Linearity graph of (a) amiloride hydrochloride and (b) furosemide

Table 3: Percentage recovery results of amiloride hydrochloride and furosemide

\begin{tabular}{|c|c|c|c|c|c|}
\hline \multirow[t]{2}{*}{ Spiked (\%) } & \multicolumn{2}{|c|}{ Percentage recovery } & \multirow{2}{*}{$\begin{array}{l}\text { Mean percentage } \\
\text { recovery }\end{array}$} & \multicolumn{2}{|l|}{$\%$ RSD } \\
\hline & $\begin{array}{l}\text { Amiloride } \\
\text { hydrochloride }\end{array}$ & Furosemide & & $\begin{array}{l}\text { Amiloride } \\
\text { hydrochloride }\end{array}$ & Furosemide \\
\hline \multirow[t]{3}{*}{80} & 99.7 & 100 & \multirow[t]{3}{*}{100.1} & \multirow[t]{3}{*}{0.74} & \multirow[t]{3}{*}{0.50} \\
\hline & 100.8 & 99.6 & & & \\
\hline & 101.1 & 100.6 & & & \\
\hline \multirow[t]{3}{*}{100} & 100.2 & 100 & \multirow{3}{*}{100.1} & \multirow{3}{*}{0.47} & \multirow{3}{*}{0.06} \\
\hline & 100 & 99.9 & & & \\
\hline & 100.9 & 100 & & & \\
\hline \multirow{3}{*}{120} & 101 & 99.7 & \multirow{3}{*}{100.7} & \multirow{3}{*}{0.23} & \multirow{3}{*}{0.61} \\
\hline & 101.4 & 100.7 & & & \\
\hline & 101 & 100.8 & & & \\
\hline
\end{tabular}

RSD: Relative standard deviation

Table 4: Results of method precision for amiloride hydrochloride and furosemide

\begin{tabular}{lll}
\hline \multicolumn{3}{l}{ \% Assay } \\
\hline S. No. & Amiloride hydrochloride & Furosemide \\
\hline 1 & 101.1 & 100.9 \\
2 & 101.7 & 100.2 \\
3 & 101 & 100.6 \\
4 & 101.6 & 100.5 \\
5 & 100.9 & 99.7 \\
6 & 101.5 & 100.2 \\
Mean \pm SD & \pm 0.35 & \pm 0.41 \\
\%RSD & 0.35 & 0.41 \\
\hline
\end{tabular}

SD: Standard deviation, RSD: Relative standard deviation
Photolytic degradation

In photolytic UV degradation, the drug degraded was $0.3 \%$ and $0.65 \%$ for amiloride hydrochloride and furosemide, respectively. However, no degradation product was observed in the chromatogram (Fig. 9).

\section{Thermal degradation}

In thermal degradation, there was no degradation peak observed in the chromatogram, and degradation was $1.2 \%$ and $2.7 \%$ for amiloride hydrochloride and furosemide, respectively (Fig. 10).

\section{Humidity degradation}

In humidity degradation, the drug degraded was $0.6 \%$ and $11.5 \%$ for amiloride hydrochloride and furosemide, respectively. However, no degradation product was observed in the chromatogram (Fig. 11). 
Table 5: Results of robustness

\begin{tabular}{|c|c|c|c|c|c|c|c|}
\hline \multirow[t]{2}{*}{ S. No. } & \multirow[t]{2}{*}{ Parameter } & \multicolumn{3}{|c|}{ Amiloride hydrochloride } & \multicolumn{3}{|c|}{ Furosemide } \\
\hline & & RT & NTP & TF & RT & NTP & TF \\
\hline \multirow[t]{2}{*}{1} & Flow rate $0.8 \mathrm{ml}$ & 2.313 & 3357 & 1.220 & 3.663 & 8027 & 1.178 \\
\hline & Flow rate $1.2 \mathrm{ml}$ & 1.643 & 2397 & 1.270 & 2.531 & 5872 & 1.197 \\
\hline \multirow[t]{2}{*}{2} & Temperature $23^{\circ} \mathrm{C}$ & 1.927 & 2881 & 1.249 & 3.158 & 6488 & 1.193 \\
\hline & Temperature $27^{\circ} \mathrm{C}$ & 1.922 & 2896 & 1.240 & 3.147 & 6511 & 1.192 \\
\hline \multirow[t]{2}{*}{3} & Wavelength $279 \mathrm{~nm}$ & 1.923 & 2846 & 1.237 & 3.141 & 6337 & 1.196 \\
\hline & Wavelength $283 \mathrm{~nm}$ & 1.921 & 2885 & 1.239 & 3.145 & 6721 & 1.192 \\
\hline
\end{tabular}

RT: Retention time, NTP: Number of theoretical plates, TF: Tailing factor

Table 6: Percentage content of marketed formulation

\begin{tabular}{|c|c|c|c|c|}
\hline Tablet & Drug & Amount taken & Amount found & \% Assay \\
\hline FRUMIL (amiloride hydrochloride & Amiloride hydrochloride & $20 \mathrm{ppm}$ & $19.91 \mathrm{ppm}$ & 99.55 \\
\hline $5 \mathrm{mg}$ and furosemide $40 \mathrm{mg}$ ) & Furosemide & $160 \mathrm{ppm}$ & $159.84 \mathrm{ppm}$ & 99.90 \\
\hline
\end{tabular}

Table 7: Forced degradation studies of amiloride hydrochloride and furosemide

\begin{tabular}{|c|c|c|c|c|}
\hline \multirow[t]{2}{*}{ Stress condition } & \multicolumn{2}{|c|}{ Amiloride hydrochloride } & \multicolumn{2}{|c|}{ Furosemide } \\
\hline & $\%$ Assay & \% Difference w.r.t control & $\%$ Assay & \% Difference w.r.t control \\
\hline Control & 99.7 & NA & 99.8 & NA \\
\hline Acid degradation & 98.4 & 1.3 & 97.9 & 1.9 \\
\hline Base degradation & 98.6 & 1.1 & 95.9 & 3.9 \\
\hline Oxidative degradation & 97.5 & 2.2 & 92.9 & 6.9 \\
\hline Photolytic degradation & 99.4 & 0.3 & 99.3 & 0.5 \\
\hline Thermal degradation & 98.5 & 1.2 & 97.1 & 2.7 \\
\hline Humidity degradation & 99.1 & 0.6 & 88.3 & 11.5 \\
\hline
\end{tabular}

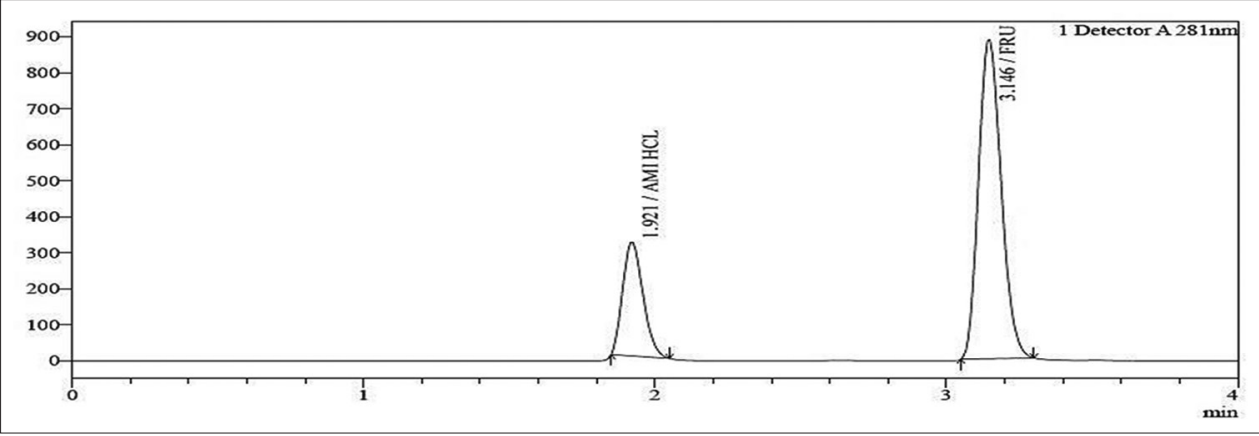

Fig. 5: Chromatogram of untreated tablet

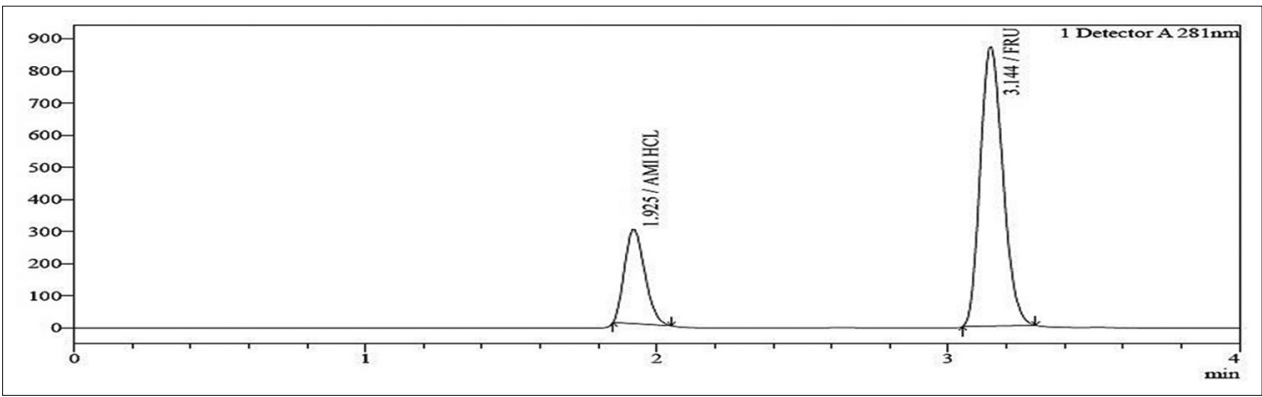

Fig. 6: Chromatogram of acid degradation

\section{CONCLUSION}

Stability indicating RP-HPLC method has been developed and for simultaneous estimation of amiloride hydrochloride and furosemide in tablet dosage form. The validated method was successfully implemented for the stress testing and analysis of amiloride hydrochloride and furosemide. The stress testing studies revealed that the method was successfully employed to resolve the degraded products from the sample. The proposed method was proved to be selective, accurate, precise, and rapid, and it can be used for the routine analysis of the amiloride hydrochloride and furosemide in the formulation. 


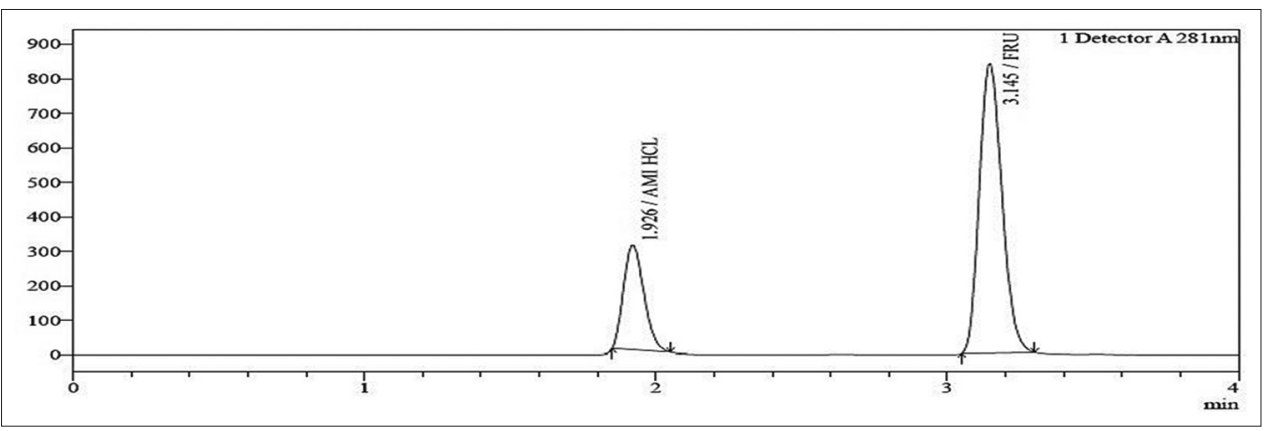

Fig. 7: Chromatogram of base degradation

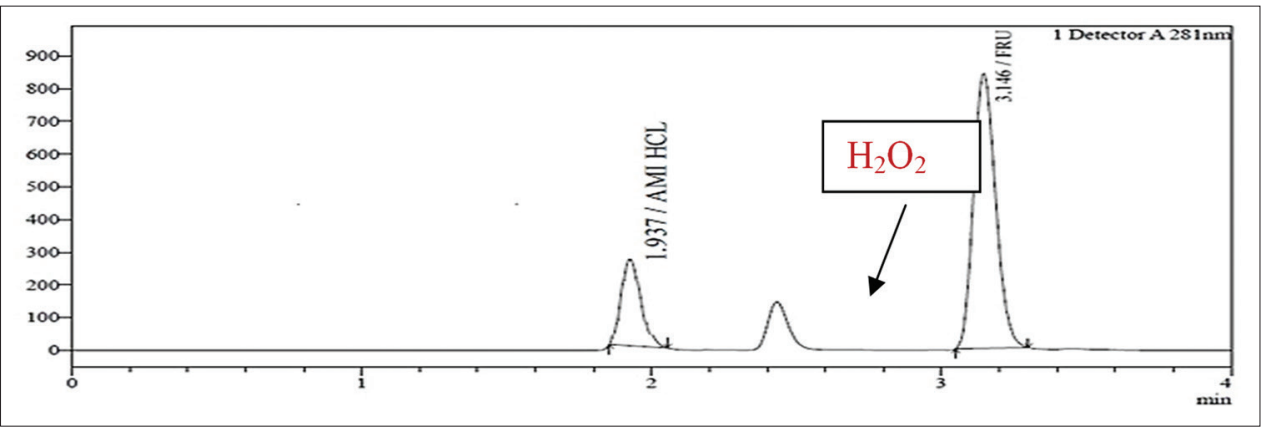

Fig. 8: Chromatogram of oxidative degradation

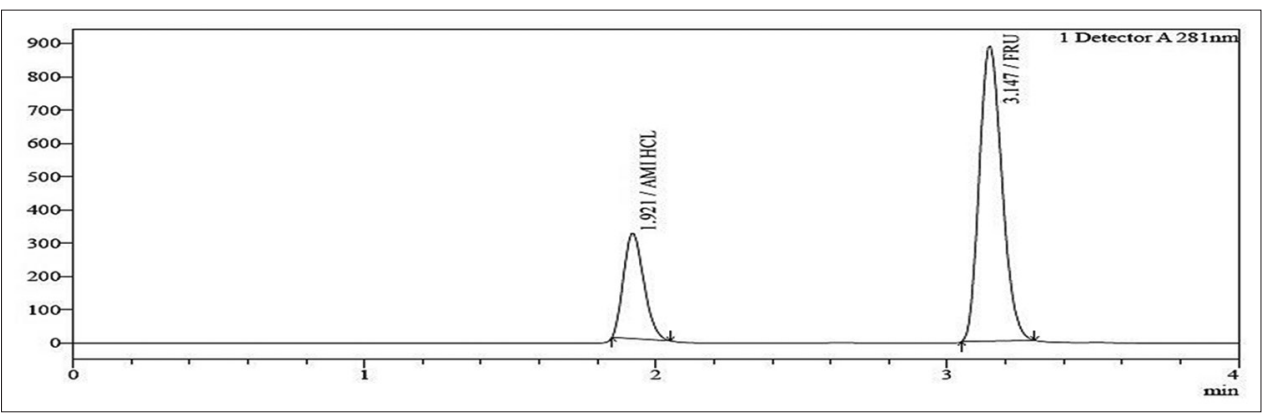

Fig. 9: Chromatogram of photolytic degradation

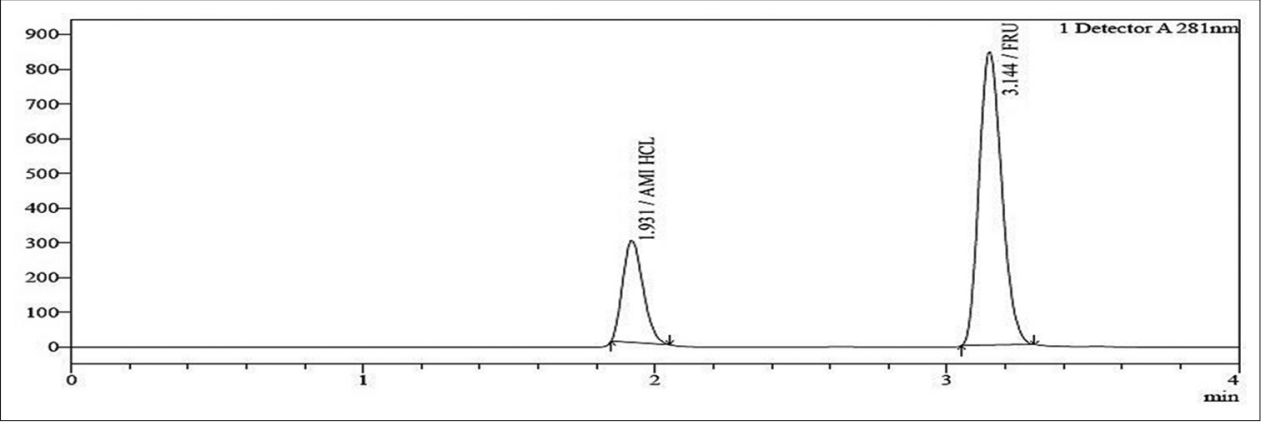

Fig. 10: Chromatogram of thermal degradation

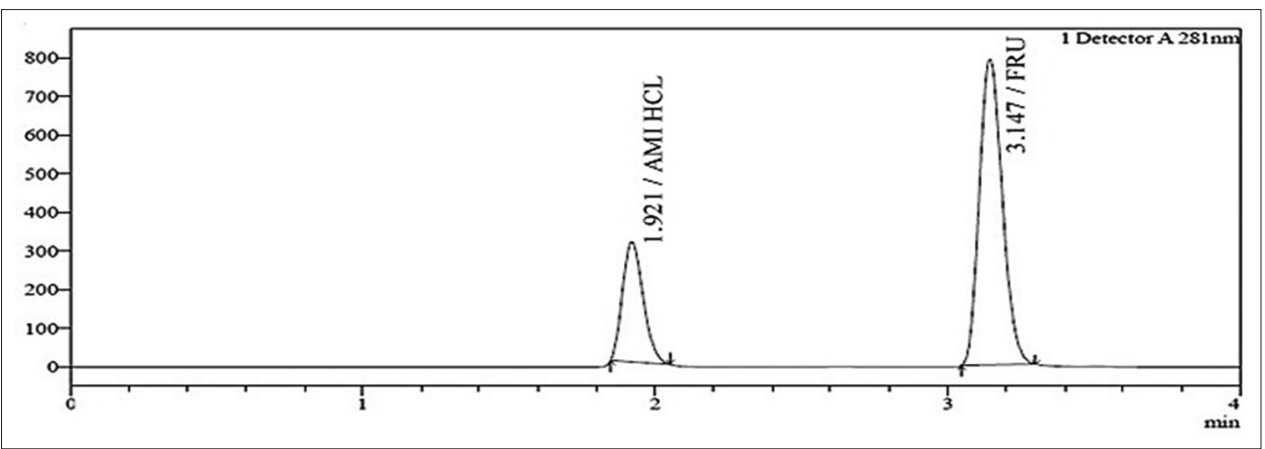

Fig.11: Chromatogram of humidity degradation 


\section{ACKNOWLEDGMENT}

The authors are thankful to our Principal Dr. Mrs. Sudha Rathod, Oriental College of Pharmacy Sanpada, Navi Mumbai, for providing a platform and facility to conduct research work. The authors are thankful to Alkem Laboratories for providing a gift sample of amiloride hydrochloride.

\section{AUTHORS' CONTRIBUTION}

All the authors have contributed equally.

\section{CONFLICTS OF INTEREST}

The authors confirm that this paper has no conflict of interests.

\section{REFERENCES}

1. Mahgoub S. Novel stability-indicating RP-HPLC method for determination of hydrochlorothiazide, amiloride Hydrochloride and timolol Maleate in tablet dosage form. Columbia Int Publ Am J Modern Chromatogr 2016;3:23-32.

2. Nagori BP, Solanki R. RP-HPLC method for simultaneous estimation of furosemide and amiloride hydrochloride in tablet formulation. Indian J Pharm Sci 2010;72:384-7.

3. Al-Saidi HK, Abdlaziz S, Semer S. Simultaneous determination of amiloride hydrochloride and hydrochlorothiazide in pharmaceuticals by derivative spectrophotometry. J Al Nahrain Univ 2010;13:52-61.

4. Mannam R, Yallamalli IM. RP-HPLC method for estimation of furosemide in rabbit plasma. J Chem Pharm Res 2018;10:1-5.

5. Tandel JN. Development and validation of RP-HPLC method for the simultaneous determination of amiloride hydrochloride and furosemide in pure and pharmaceutical dosage form. Eur J Anal Chem 2017;12:385- 94

6. Kopuri G, Anusha K, Rao DS. Development of a new HPLC method for simultaneous estimation of amiloride and hydrochlorothiazide. J Chem Pharm Sci 2015;8:661-3.

7. Narasimham YS, Barhate VD. Development and validation of stability indicating UPLC method for the simultaneous determination of betablockers and diuretic drugs in pharmaceutical dosage forms. J Chem Metrol 2010;4:1-20.

8. Tengli AR, Gurupadayya BM. Method development and validation of a tablet dosage form containing losartan, atenolol and hydrochlorothiazide using internal standard by RP-HPLC. J Chromatogr Separation Tech 2013;4:1-5.

9. Devanna N, Dudekula B, Ramachandraiah C. Development and validation for the simultaneous estimation of dolutegravir and lamivudine in drug product by RP-HPLC. Int J Res Pharm Nano Sci 2017;6:173-80.

10. Thomas A, Bhosale S, Nanda R. Formulation of solid dosage form containing clopidogrel and cilostazol and its HPLC analysis. Int $\mathrm{J}$ Pharm Pharm Sci 2017;9:12-8.

11. Suneetha A, Kathirvel S, Ramachandrika G. A validated RP HPLC method for simultaneous estimation of lopinavir and ritonavir in combined dosage form. Int J Pharm Pharm Sci 2011;3:49-51.

12. Swetha A, Kuber BR. A novel stability-indicating reverse phase liquid chromatographic method for the simultaneous estimation of metformin and teneligliptin in pure and pharmaceutical formulations. Int J Pharm Pharm Sci 2017;9:163-9.

13. Jain V, Shaikh MS. Simultaneous RP-HPLC analysis of quercetin and kaempferol in different plant parts of cissusquadrangularis. Int J Pharm and Pharm Sci 2016;8:138-42

14. Marineni B, Reddy TS. Development and validation of stabilityindicating RP-HPLC assay method for azacitidine and its bulk drug. Int J Pharm Pharm Sci 2014;6:240-4. 